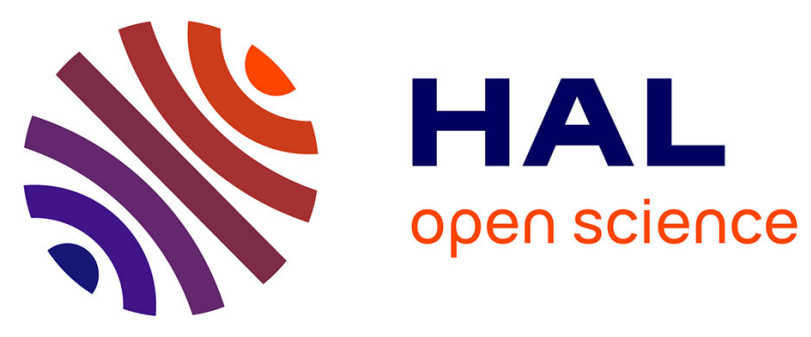

\title{
Learning What You Know: How Prior Knowledge Impairs New Associative Learning in Early AD
}

Pierre-Yves Jonin, Quentin Duché, Elise Bannier, Isabelle Corouge, Jean-Christophe Ferré, Serge Belliard, Christian Barillot, Emmanuel J. Barbeau

\section{To cite this version:}

Pierre-Yves Jonin, Quentin Duché, Elise Bannier, Isabelle Corouge, Jean-Christophe Ferré, et al.. Learning What You Know: How Prior Knowledge Impairs New Associative Learning in Early AD. AAIC 2019 - Alzheimer's Association International Conference, Jul 2019, Los Angeles, United States. pp.1-2. inserm-02383941

\section{HAL Id: inserm-02383941 https://www.hal.inserm.fr/inserm-02383941}

Submitted on 28 Nov 2019

HAL is a multi-disciplinary open access archive for the deposit and dissemination of scientific research documents, whether they are published or not. The documents may come from teaching and research institutions in France or abroad, or from public or private research centers.
L'archive ouverte pluridisciplinaire HAL, est destinée au dépôt et à la diffusion de documents scientifiques de niveau recherche, publiés ou non, émanant des établissements d'enseignement et de recherche français ou étrangers, des laboratoires publics ou privés. 


\title{
Learning What You Know: How Prior Knowledge Impairs New Associative Learning in Early AD
}

\author{
Pierre-Yves Jonin ${ }^{1,2,3}$, Quentin Duché ${ }^{2}$, Elise Bannier ${ }^{2,4}$, Isabelle Corouge ${ }^{2,4}$, Jean-Christophe \\ Ferré $^{4}$, Serge Belliard ${ }^{3}$, Christian Barillot ${ }^{2}$, Emmanuel J. Barbeau ${ }^{1}$. \\ (1)Brain and Cognition Research Center, CNRS UMR 5549, Université de Toulouse Paul \\ Sabatier, Toulouse, France \\ (2)IRISA, UMR CNRS 6074, VisAGeS U1228, INSERM, INRIA, Université de Rennes 1, \\ Rennes, France \\ (3)Neurology Department, Pontchaillou University Hospital, Rennes, France \\ (4)Radiology Department, Pontchaillou University Hospital, Rennes, France
}

\begin{abstract}
Background: Prodromal AD impairs associative learning. AD patient memory complaints refer to their daily routine, which usually involves highly familiar stimuli. However, memory tests involve less familiar stimuli (e.g. isolated words or pictures). Therefore we ignore whether prior knowledge affects memory formation in AD. During learning, stimuli repetition yields neural adaptation effects (signal suppression or enhancement), allowing the functional mapping of brain networks. Here, we manipulated prior knowledge and repetition to investigate whether prior knowledge impacts the neural underpinnings of associative encoding in AD.
\end{abstract}

Method: 17 patients with Mild Cognitive Impairment due to AD (AD-MCI, Albert et al., 2011) and 19 controls underwent fMRI. They learned face-scene associations presented twice in the scanner. Pre-experimental knowledge (PEK) trials involved famous faces while Experimental Knowledge (EK) trials involved unknown faces repeatedly presented prior to the scanned encoding session. Study events were categorized as associative hits, associative misses or misses after a recognition memory test administered outside the scanner. The BOLD signal was modeled using a factorial design within the general linear model framework. The factors were Subsequent associative memory, Prior knowledge, and Repetition. We computed the interaction contrast between Repetition and Prior knowledge to test whether encoding networks could be altered by prior knowledge. In the resulting clusters, we ran within- and between-groups ANOVAs seeking for subsequent memory effects, namely superior betas weights for associative hits over associative misses.

Result: PEK and EK yielded similar associative memory performance in AD-MCI, while PEK trials led to a $28 \%$ increase in associative memory in controls. Prior knowledge $\mathrm{x}$ Repetition interaction was found within key regions of the memory retrieval and encoding networks in controls, but AD-MCI showed aberrant or absent neural adaptation. Subsequent memory analyses provided evidence for the involvement of the right hippocampus in both groups for EK. For PEK associative memory however, only controls showed a memory effect within right anterior subhippocampal structures.

Conclusion: In $\mathrm{AD}$, tau pathology starts within anterior subhippocampal regions (entorhinal and perirhinal cortices). Thus, our findings that subhippocampal, not hippocampal, activation underlie the inability of the patients to benefit PEK in new learning open perspectives for further diagnostic and prognostic research. 


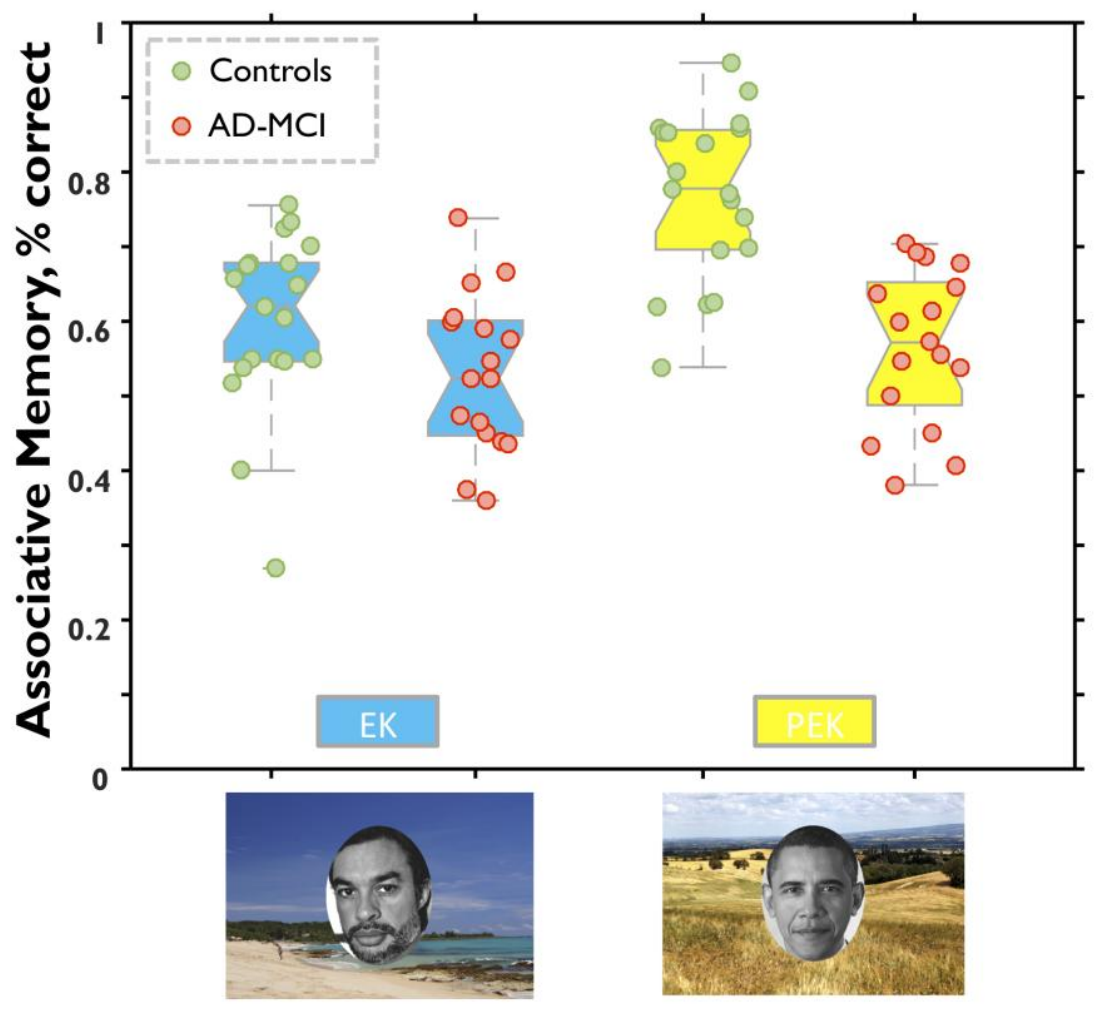

Figure 1. Associative Memory Performance

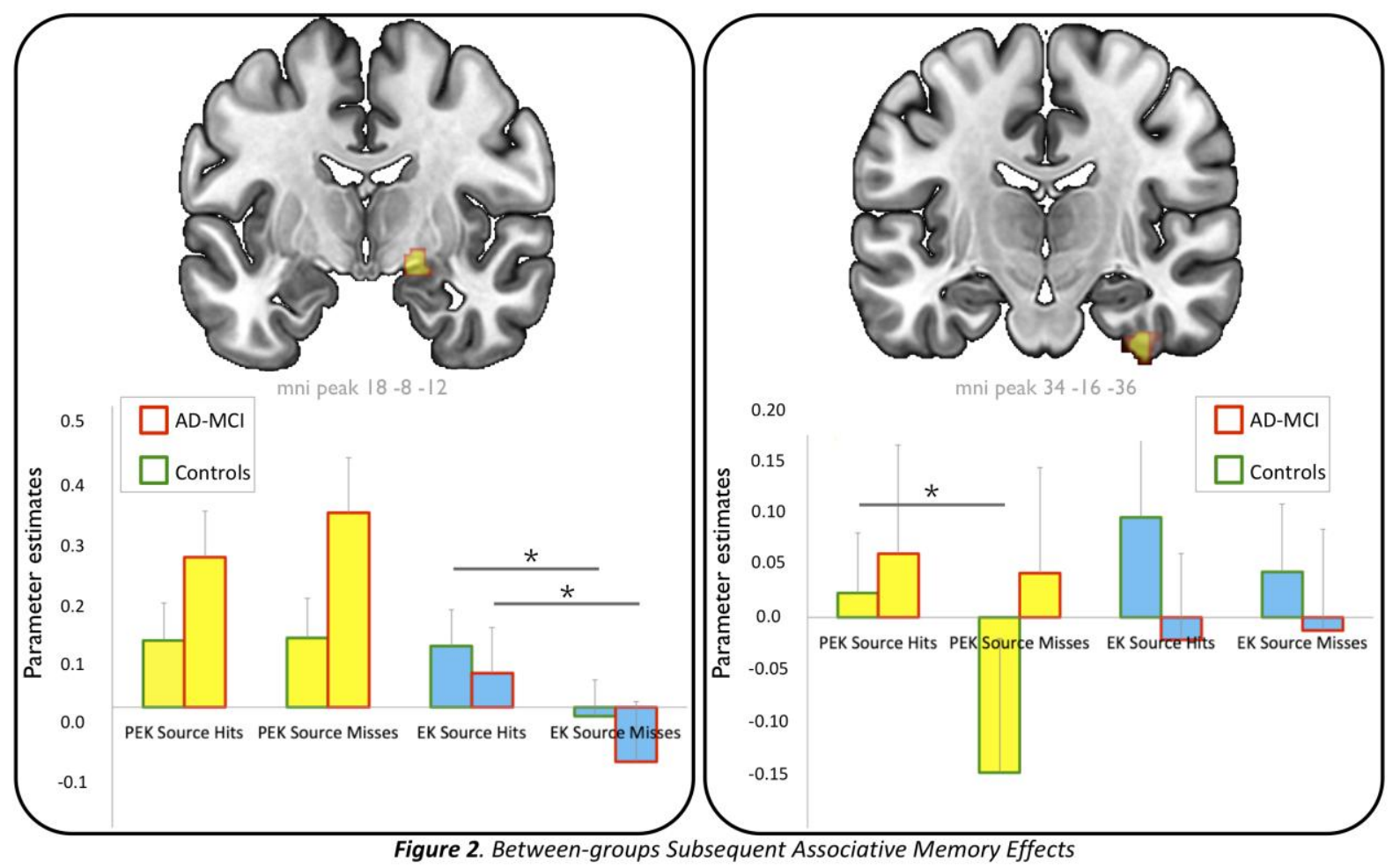

Figure 2. Between-groups Subsequent Associative Memory Effects 